\title{
Costs related to serious road injuries: a European perspective
}

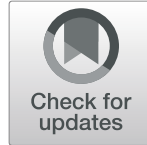

\author{
Annelies Schoeters ${ }^{1 *}$ (D) Wim Wijnen ${ }^{2}$, Laurent Carnis ${ }^{3}$, Wendy Weijermars ${ }^{4}$, Rune Elvik ${ }^{5}$, Stijn Daniels ${ }^{6}$ and \\ Heiko Johannsen ${ }^{6}$
}

\begin{abstract}
Introduction: Costs related to road crashes represent an important societal burden. Additionally they constitute an essential input variable to assess the cost efficiency of road safety measures. While most attention is usually spent on costs related to fatal crashes, this paper focuses on costs related to serious injuries.

Method: A review of these costs is presented based on different data sets and methods.

Results: A survey collecting crash cost estimates in European countries shows considerable variation in the costs related to serious injuries. The reported cost per serious injury varies between $€ 28,205$ and $€ 975,074$ and the total costs related to serious injuries vary between $0.04 \%$ and $2.7 \%$ of a country's GDP. The applied methodology to estimate human costs appears to have a large influence. Other potential explanations are the applied definition for seriously injured victims, the registration procedure of crashes with serious injuries and the cost components that are included. Detailed analyses of medical costs and production loss that are based on country-specific datasets show the importance of assessing medical costs on the long term and taking into account the variation of these costs for different subgroups of traffic victims. A comparison of approaches to estimate monetary values for human costs shows that most countries use the Willingness To Pay method. While having a sound theoretical background, this method is rather limited in the specification of injuries. The use of Quality Adjusted Life Years gives the possibility to provide values for a larger diversity of injury types.
\end{abstract}

Keywords: Serious injuries, Costs, Road safety policy

\section{Introduction}

Road crash cost estimates can be used in economic assessments of road safety programs. These costs reflect the monetary valuation of the benefits of road safety improvements. Different studies have been dedicated to road crash costs and the costs of fatalities [30], while not much attention has been given to the costs of serious injuries. However, the consequences of serious road injuries might represent important societal costs. Given their high number, large health impact and their slow reduction over the last decades (as opposed to fatal injuries), serious road injuries are more commonly being adopted as an additional road safety performance indicator [27], for example by the

\footnotetext{
*Correspondence: Annelies.Schoeters@vias.be

${ }^{1}$ Vias institute, Brussels, Belgium

Full list of author information is available at the end of the article
}

European Commission [13]. The definition of serious road traffic injuries differs between EU member states. While most countries use police data and define these victims as casualties admitted to a hospital, other countries use hospital data and base their definition on the injury severity level [28]. In 2013 the European Commission established a common definition for serious injuries as nonfatal road traffic casualties with an injury level of MAIS3 $+^{1}[14]$.

\footnotetext{
${ }^{1}$ According to the AIS (Abbreviated Injury Scale) system every individual injury described in a 7 digit code of which the last digits indicate the mortality risk in an ordinal scale ranging from AIS 1 superficial injury; to AIS 6 - no medical treatment possible, i.e. $100 \%$ mortality risk [4]. In order to summarise the whole body injury severity, especially for victims with multiple injuries, the Maximum AIS (MAIS) is used.
} 
However the methodologies for estimating MAIS3+ casualties still differ widely among EU countries.

Research about costs of serious injuries so far has been scarce. This is probably related to the fact that serious injuries are only relatively recently really used as a performance indicator. This paper tries to fill this knowledge gap in an elementary way. The paper presents the results of a review of these costs in 32 European countries that was conducted in the framework of the H2020 project SafetyCube. Next to comparing the official cost estimates in European countries, this paper examines three cost components that are most relevant for serious injuries in more detail. Medical costs and costs related to production loss are examined by identifying their influencing factors. Finally more insight in human costs is provided by discussing and comparing three approaches to put monetary values to human costs.

The socio-economic costs of serious road injuries consist of different cost components. Based on classifications in the international literature $[3,26,29,30]$, we distinguish six cost components for road crashes and casualties:

- Medical costs

- Production loss: the loss of production or productive capacities

- Human costs: immaterial cost of lost quality of life and lost life years

- Administrative costs: police, fire service, insurance, legal costs

- Property damage: damage to vehicles, infrastructure, freight and personal property

- Other costs, such as costs of congestion resulting from road crashes, vehicle unavailability and funeral costs

A further classification of these cost components based on the European COST313 guidelines [3] distinguishes between "injury-related costs" and "crash-related costs". The injury-related costs, which are most relevant for serious road injuries, are: medical costs, costs related to production loss, human costs and certain cost items that are categorized as other costs.

Section 2 describes the cost estimates in the different European countries that were collected by means of a survey. It further examines the origin of the observed differences between countries. Section 3 provides additional insight into the factors influencing medical costs and costs related to production loss, using different country-specific studies. Finally, since human costs represent the largest share in the costs related to serious injuries, the different approaches to calculate this type of cost are examined and compared.

\section{Costs of serious road injuries in the European countries}

\subsection{Data collection}

By means of a survey that was carried out in 2016, crash cost estimates were collected for 32 European countries (EU28 + Iceland, Norway, Serbia and Switzerland). The data collection was a joint effort between the EU projects SafetyCube (https://www.safetycube-project.eu/) ${ }^{2}$ and InDeV (http://www.indev-project.eu/). The survey included questions concerning the national cost estimates per crash and per casualty by level of severity, the cost estimates per cost component and the total costs of crashes. Furthermore information was inquired on the methodology that was applied for assessing such figures and the databases that were used. The collected information was integrated into a SQLite database and multiple consistency checks were carried out, resulting in several corrections. In order to be able to compare costs from different countries, all values are expressed in EUR price level 2015 and adjusted for relative income differences using Purchasing Power Parities (PPP) from Eurostat.

\subsection{The costs related to serious injuries compared between the different European countries}

The results of the survey indicate that the official national cost estimates for serious injuries differ considerably between the European countries. This is the case for both the unit cost per serious injury and the total costs related to serious injuries (Table 1). The values for the cost per serious injury range from $€ 28,205$ in Latvia to $€ 975,074$ in Poland. The median value is $€ 254,777$. Geographically, the values per serious injury appear to be higher in Northern European countries and in some Eastern European countries (Poland, Estonia and Hungary) (Fig. 1).

With regards to the total costs related to serious injuries, these costs are presented as a percentage of the Gross Domestic Product (GDP) of a country using data for 2015 from Eurostat. In that way, the effect of factors influencing the number of casualties, such as the number of inhabitants and the size of the country, are cancelled out so comparisons between countries are more meaningful $[12,29]$. As can be seen in Table 1, total costs related to serious injuries as a percentage of GDP also vary considerably. The total costs range from $0.04 \%$ of GDP in Ireland to $2.7 \%$ of GDP in Poland. The median percentage is $0.3 \%$. As opposed to the unit cost per serious injury, there is no clear geographical pattern (Fig. 2).

\footnotetext{
${ }^{2}$ The results of the survey can be found in the SafetyCube project deliverable 7.3: Costs related to serious road injuries .
} 
Table 1 Cost per serious injury and total costs related to serious injuries as percentage of GDP, per country (EUR 2015, adjusted for PPP)

\begin{tabular}{|c|c|c|}
\hline Country & Cost per serious injury & Total costs related to serious injuries as $\%$ of GDP \\
\hline Austria & 381,285 & 1.18 \\
\hline Belgium & 307,364 & 0.45 \\
\hline Bulgaria & 220,390 & 1.33 \\
\hline Croatia & 290,042 & 2.11 \\
\hline Cyprus & 135,535 & 0.29 \\
\hline Czech Republic & 295,199 & 0.48 \\
\hline Denmark & 344,536 & 0.23 \\
\hline Estonia & 959,011 & 2.21 \\
\hline Finland & 671,383 & 0.17 \\
\hline France & 368,029 & 0.45 \\
\hline Germany & 119,480 & 0.27 \\
\hline Greece & 252,277 & 0.12 \\
\hline Hungary & 501,194 & 2.59 \\
\hline Iceland & 364,914 & 0.43 \\
\hline Ireland & 225,511 & 0.04 \\
\hline Italy & 211,860 & 0.55 \\
\hline Latvia & 28,205 & 0.51 \\
\hline Lithuania & 89,804 & 0.94 \\
\hline Luxembourg & NA & NA \\
\hline Malta & 203,913 & 0.70 \\
\hline Netherlands & 269,149 & 0.74 \\
\hline Norway & 845,812 & 0.19 \\
\hline Poland & 975,074 & 2.65 \\
\hline Portugal & 136,365 & 0.20 \\
\hline Romania & NA & NA \\
\hline Serbia & NA & NA \\
\hline Slovakia & 141,504 & 0.20 \\
\hline Slovenia & 247,550 & 0.75 \\
\hline Spain & 254,777 & 0.46 \\
\hline Sweden & 399,728 & 0.21 \\
\hline Switzerland & 214,023 & 0.49 \\
\hline United Kingdom & 227,979 & 0.20 \\
\hline
\end{tabular}

\subsection{Potential explanations for differences in the cost estimates between European countries}

There are several potential explanations for the large differences observed in the unit costs related to serious injuries. Among these explanations are:

- differences in the definition of a serious injury;

- differences in the cost components and cost items that have been included;

- differences in the methodology used to calculate the cost components;

- differences in the reporting rate of serious injuries.

- differences in the GDP per capita.
With regards to the total costs related to serious injuries, a supplementary potential explanation is:

- differences in the level of road safety.

\subsubsection{Definition of a serious injury}

The survey shows that the definition of a serious injury that is applied in national cost estimations varies strongly between the surveyed countries. While it is difficult to find a pattern, it seems that countries where a serious injury is defined more strictly, i.e. by a hospital admission of more than $48 \mathrm{~h}$ or by permanent disability payments, have a higher cost per serious injury. Countries that use a 

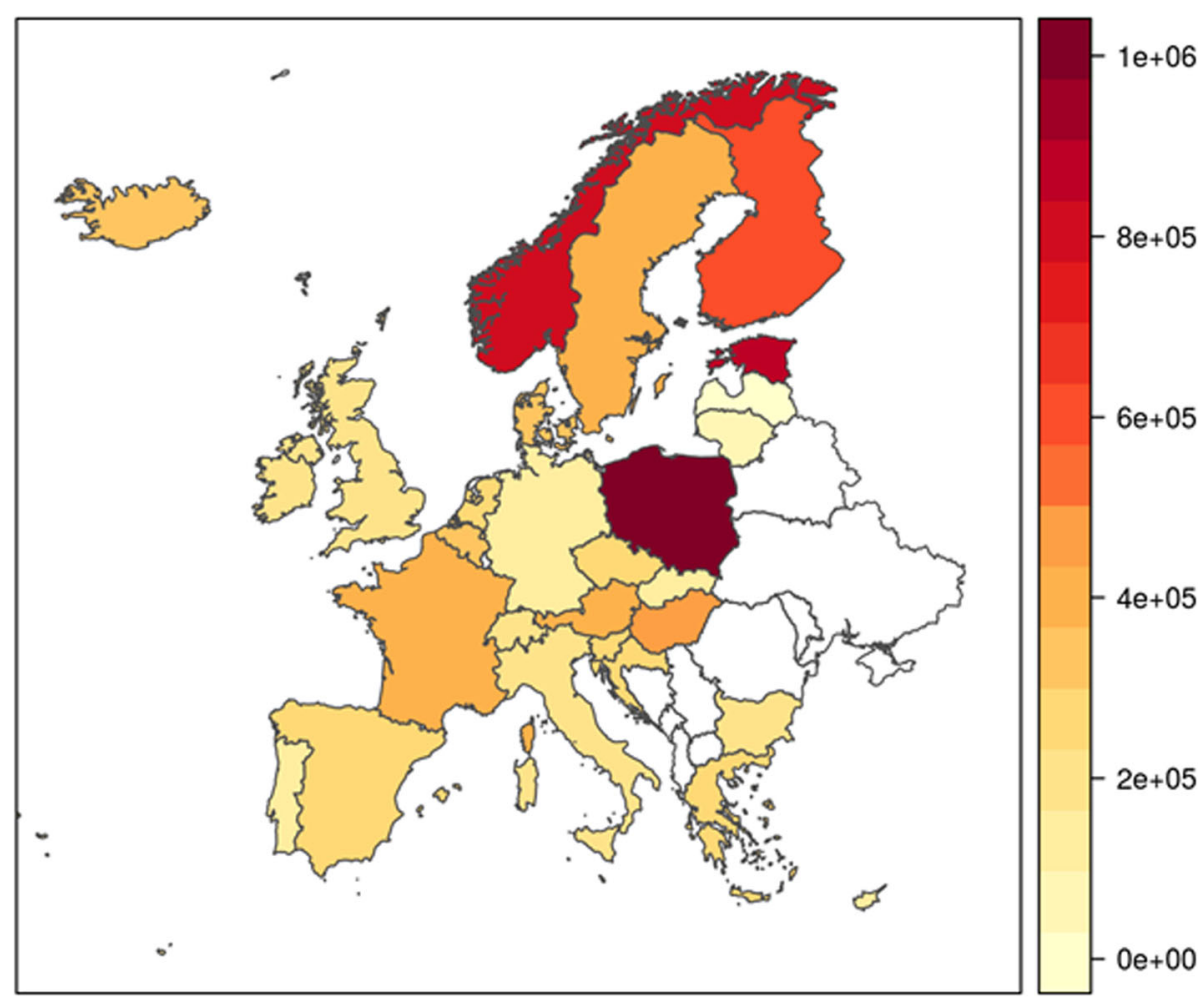

Fig. 1 Unit cost per serious injury (EUR 2015, adjusted for PPP)

definition of a hospital admission of more than $24 \mathrm{~h}$ show on the other hand, average to low costs per unit $(€ 368,029$ to $€ 11,948)$. However, the large variation in the unit costs among countries that use the same definition indicates that there are also other factors on the basis of the observed differences.

\subsubsection{Cost components and items included}

Based on classifications in the international literature [3, $26,29,30]$, we have defined six cost components that should be included in the calculation of the costs of serious injuries. Table 2 shows the number of countries that have included each cost component in the cost per serious injury. It is notable that not all countries have included the same components. Furthermore most countries have included the injury-related cost components, while the crash-related components are included by only 6 to 10 countries. These differences could probably explain part of the variability in the cost per serious injury.

Besides including a different number of cost components, the contribution of the cost components to the unit cost per serious injury, also differs between countries (Fig. 3). While in most countries the human cost component contributes the most to the unit costs of serious injuries, in some countries the costs related to production loss and the medical costs take a large part.
Further differences can arise from different cost items that are included in the estimation of specific cost components. With regards to medical costs, most countries include the costs related to in-patient treatment, outpatient treatment and the emergency department. Nonhospital treatment and costs related to aids and appliances are included in fewer countries. Regarding the costs related to production loss, most countries only include future (market) production loss, while only a few countries also include non-market loss or friction costs.

\subsubsection{Methodology}

Based on the international literature, we have also defined good practices regarding the methodology to estimate the different components. While all countries generally use the recommended method to calculate medical costs (Restitution Cost $\operatorname{method}^{3}$ ) and costs related to production loss (Human Capital method ${ }^{4}$ ), the

\footnotetext{
${ }^{3}$ This approach implies a calculation of the costs of the resources that are necessary to restore road casualties to the situation, which would exist if they had not been involved in a road crash. If available, market prices are used to calculate these costs [30].

${ }^{4}$ This approach implies that the value for society of the loss of productive capacities is calculated. In general, these costs are calculated by multiplying the period of time road casualties are not able to work due to the crash by a valuation of the production per person per unit of time [30].
} 


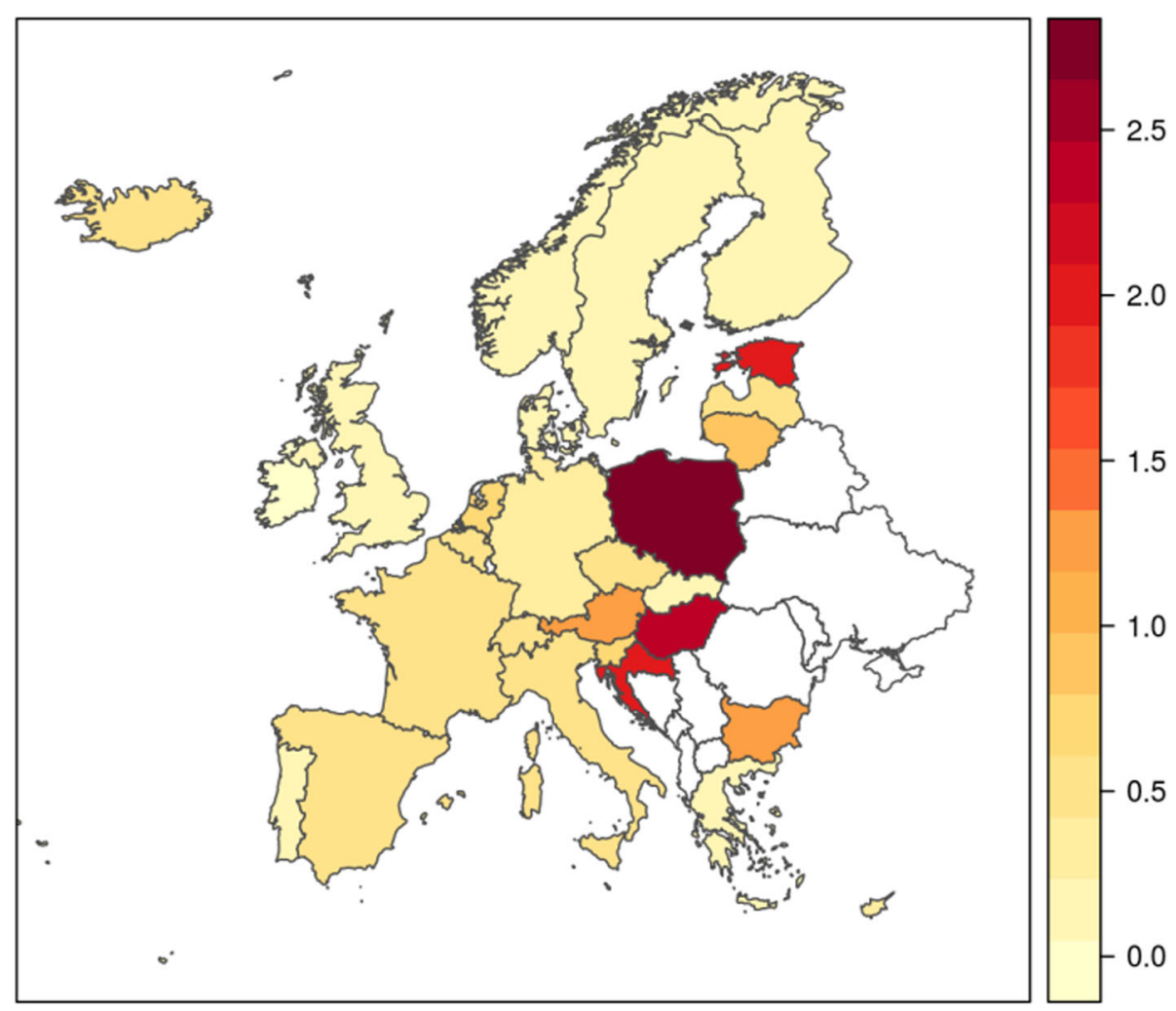

Fig. 2 Total costs related to serious injuries as percentage of GDP

method used to calculate human costs differs among countries. While the Willingness To Pay (WTP) method is generally recommended, other methods such as the Human Capital approach and the Restitution Costs approach are also used by some countries. In this case the Restitution Costs method means that the valuation of the quality of life is based on compensation payments by courts or insurances.

Variation in the method used to calculate human costs can have a large influence on the costs related to serious injuries because human costs generally represent a very large share of the cost per serious injury. The positive relationship between the human cost component of a serious injury and the unit cost of a serious injury is illustrated in Fig. 4. A linear regression was calculated to predict the unit cost of a serious injury based on the human cost component. A significant regression equation was found $(F(1,18)=39.94, p<0.001)$ with an Adjusted
$R^{2}$ of 0.6721 . The unit cost of a serious injury equals $49.730+1.301$ (human cost component). Moreover, the effect of the applied method is demonstrated in Fig. 4 Countries that used the WTP method show the largest human cost (and thus cost per serious injury); if a factor 'WTP - non-WTP' is included in a linear regression model, the fraction of explained variation increases to 0.88 (Adjusted $R^{2}=0.8756, p<0.001$ ).

\subsubsection{Reporting rate}

Differences in the reporting rate of serious injuries by the police or by hospitals also explain some variation in the cost per serious injury. A higher reporting rate usually implies that more injuries of a lower severity are included in the cost calculations. This results in a relatively lower value per serious injury. When the reporting rate is presented as the number of serious injuries relative to the number of fatalities, it is shown that

Table 2 Number of countries for which cost components are included in the calculation of the cost per serious injury

\begin{tabular}{llll}
\hline Injury-related cost components & & Crash-related cost components \\
\hline Medical costs & 16 & Property damage & 6 \\
Production loss & 17 & Administrative costs & 10 \\
Human costs & 21 & Other costs & 9 \\
\hline
\end{tabular}




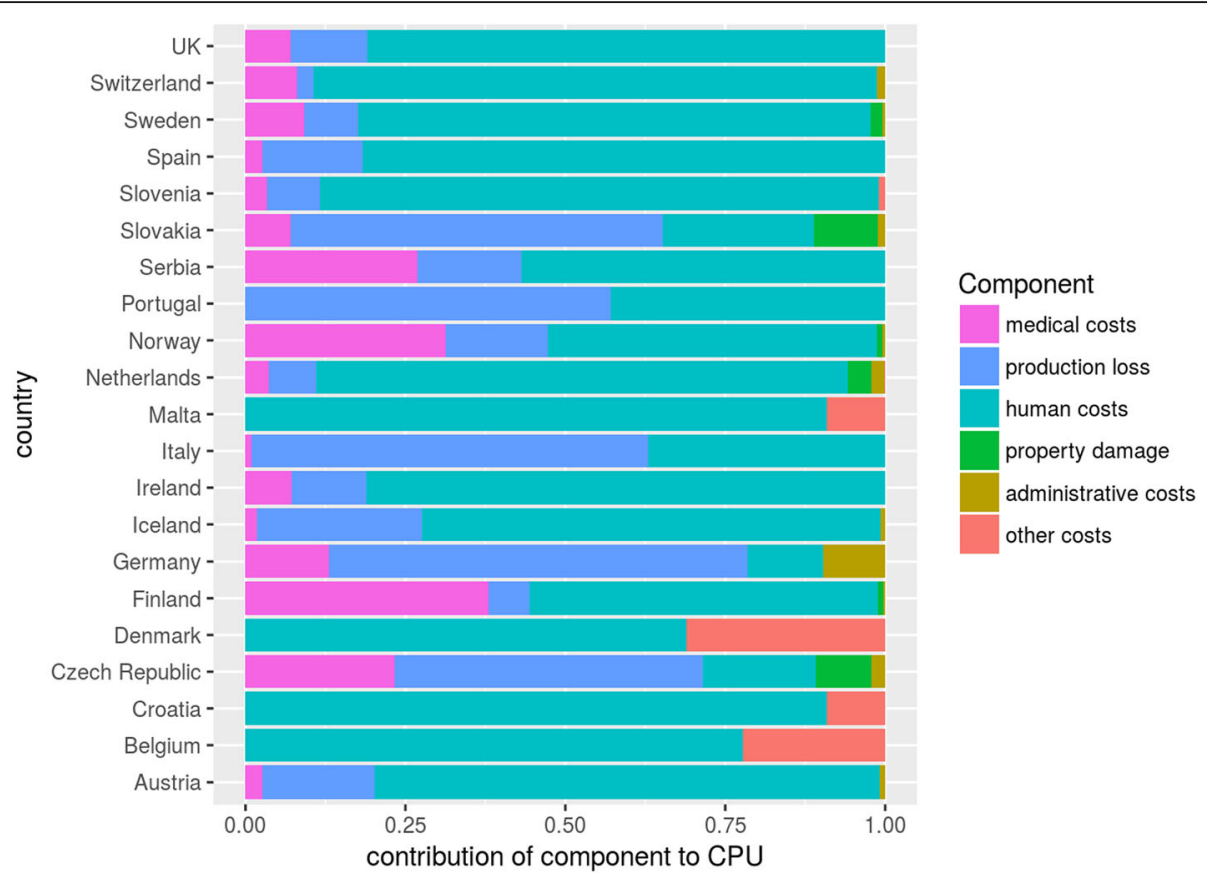

Fig. 3 Contribution of cost components to the unit cost per serious injury (CPU)

a higher reporting rate is accompanied by relatively lower costs of a serious injury. After exclusion of two outliers, a linear regression shows that the reporting rate explains $23 \%$ of the variation of the cost of serious injuries (Adjusted $R^{2}=0.23, p<0.01$ ).

\subsubsection{Level of road safety}

Regarding the differences in the total costs of serious injuries as a percentage of GDP, there are several explanations. Next to the influence of the unit cost of a serious injury, for which the explanations are given above, these

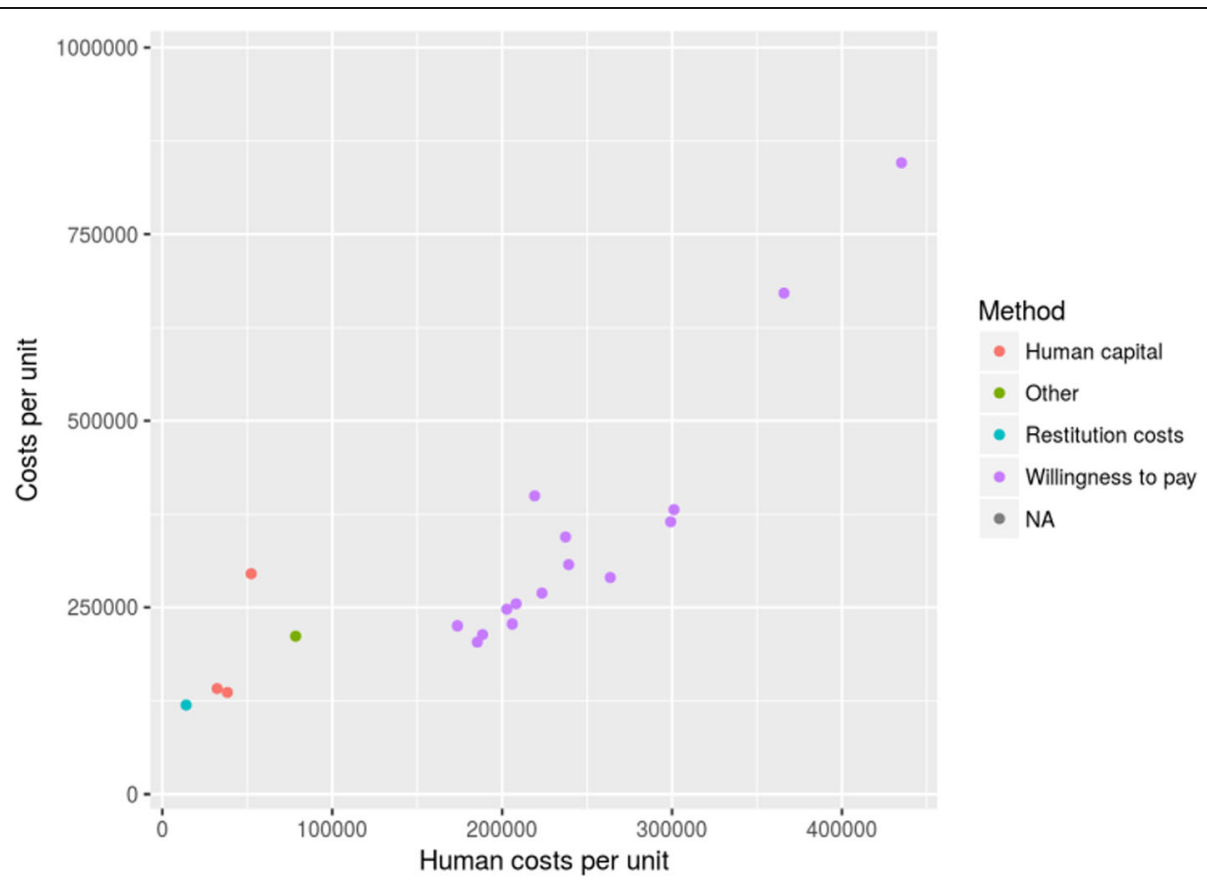

Fig. 4 Relation between cost per serious injury and human cost per serious injury, for different methods to calculate human costs (EUR 2015, adjusted for PPP) 


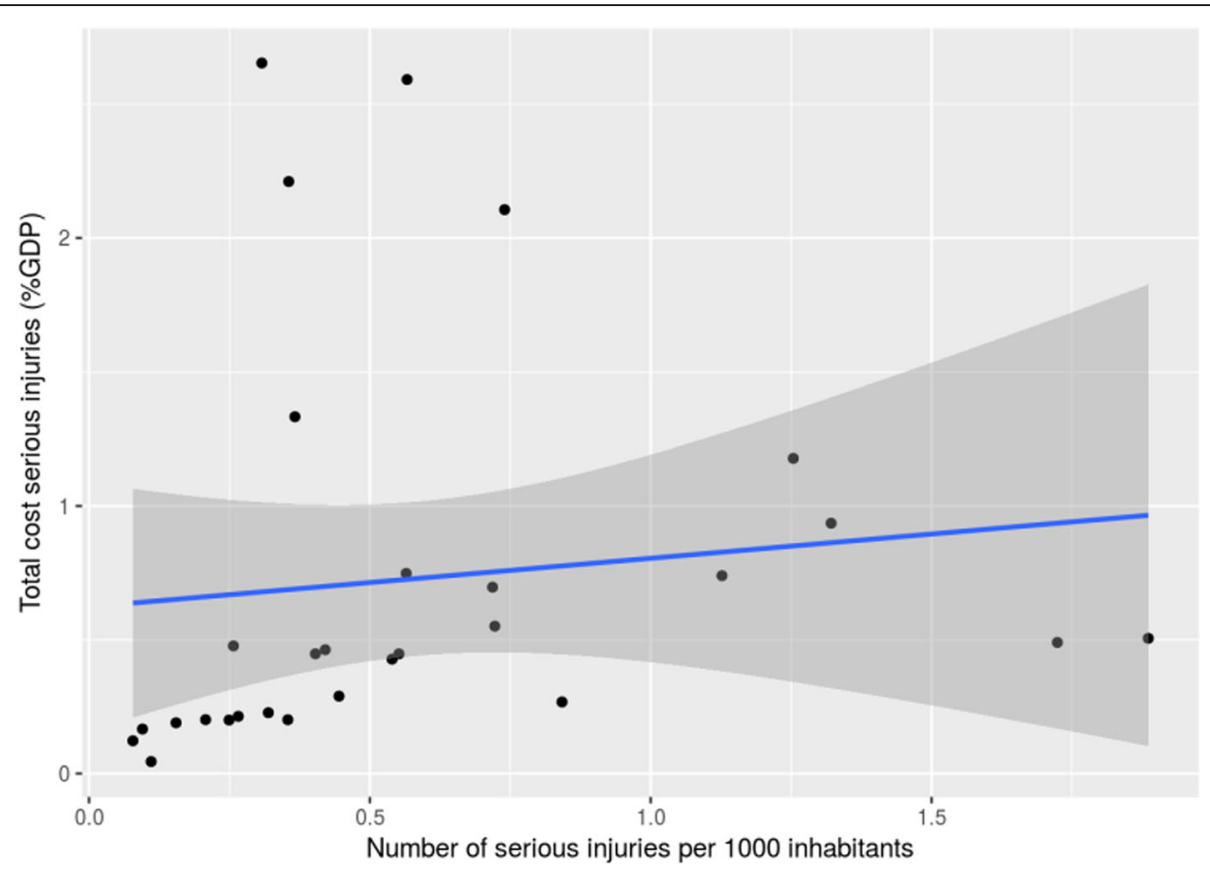

Fig. 5 Relation between number of serious injuries per million inhabitants, and total costs related to serious injuries as percentage of GDP (outliers are included)

variations can reflect differences in the level of road safety. A better road safety performance should result in lower road crash costs. The relationship between the number of serious injuries per inhabitant and the total costs of serious injuries as percentage of GDP is examined in Fig. 5. The linear regression shows however no relationship (Adjusted $R^{2}=-0.02, p>0.1$ ). After removing 5 outliers (Poland, Hungary, Estonia, Croatia and Bulgaria), the relationship becomes highly significant and the level of road safety explains $40 \%$ of the variability of the costs as a percentage of GDP (Adjusted $R^{2}=0.40, p<0.001$ ). Apart from the fact that all outliers are situated in Eastern Europe, there is not enough information to give an explanation why the effect is absent in these countries. Further research is necessary to give more insights.

\section{An insight in the factors influencing medical costs and costs related to production loss}

The results of the survey on crash costs show furthermore the relevance of medical costs and costs related to production loss for serious injuries. These cost components represent on average $18 \%$ of the cost of a serious injury. Different studies conducted in European countries that provide more detailed analyses on medical costs and costs related to production loss are consulted to get more insight in the factors that influence these cost components. This information can contribute to a better estimation of these costs and can support policymakers in defining a policy to reduce these costs.

\subsection{Factors influencing medical costs}

Table 3 gives an overview of the consulted studies that deal with medical costs of road casualties. All studies included hospitalized road casualties.

All studies showed that certain characteristics of road victims have a significant influence on the amount of medical costs. Devos [11] showed that an older age, a low socio-economic status, a higher severity of injuries, certain types of injuries, and certain pre-existing comorbidities lead to significantly higher acute hospital costs. The influence of most of these characteristics was confirmed in a study by Achit [1] in which the total amount of medical costs attributable to a road crash was examined. Moreover, Achit identified higher costs for male victims and for motorcyclists. This implies that when estimating medical costs for cost-benefit analysis, one should ideally take into account certain characteristics of potential traffic victims such as the age, socio-economic status and health state. Another implication for policymakers is that an increasingly older population (with more comorbidities) can increase future medical costs.

Moreover Devos et al. [11] and Achit [1] identified the long-term cost trajectories of all medical costs that are related to road injuries. Both studies found that medical costs were still significantly higher 1 year after the occurrence of the road crash. This finding stresses the importance of including non-hospital costs and more generally non-acute medical costs in the estimation of medical costs of seriously injured road casualties. 
Table 3 Description of the studies that provide more detailed analyses on medical costs

\begin{tabular}{llll}
\hline & Database used & Dependent variable & Influencing factors \\
\hline Devos, 2017 [10] & $\begin{array}{l}\text { Linked hospital- medical insurance } \\
\text { dataset, covering the whole } \\
\text { Belgian population }\end{array}$ & Acute hospital costs & $\begin{array}{l}\text { Socio-demographic characteristics } \\
\text { and clinical conditions }\end{array}$ \\
Devos et al., 2017 [11] & $\begin{array}{l}\text { Linked hospital- medical insurance } \\
\text { dataset, covering the whole } \\
\text { Belgian population }\end{array}$ & $\begin{array}{l}\text { All medical costs attributable } \\
\text { to a road injury until 1 year } \\
\text { after the crash }\end{array}$ & Road user type and injury severity \\
Achit, 2015 [1] & $\begin{array}{l}\text { All medical costs attributable } \\
\text { sample for the French population }\end{array}$ & $\begin{array}{l}\text { Age, gender, road user type, injury } \\
\text { to a road injury until 4 years } \\
\text { after the crash }\end{array}$ & $\begin{array}{l}\text { France } \\
\text { severity, medical spending before } \\
\text { the crash }\end{array}$ \\
\hline
\end{tabular}

Furthermore, characteristics of the road victims and their injuries also seem to have an influence on the long term cost trajectory of their medical costs attributable to a road crash. Devos et al. [11] found that cost patterns 1 year after a road crash, generally show a large increase in medical costs immediately after the crash followed by a steady decrease. A comparison of the cost trajectories of different injury severities shows similar patterns that differ in magnitude. The initial increase of costs appears to be much larger for more severe injuries. Achit [1] identified three groups on the basis of the cost pattern over the 4 years after the crash. While for the majority of the road victims the medical costs have disappeared after 2 years, this is not the case for two types of victims. The first of these types shows a very high increase of medical costs during the first year after the crash, which only disappears after 4 years. This group consists of slightly older and more severely injured victims. The second group are the victims that had already higher medical costs previous to the crash and were in a worse health state. They are characterized by an older age and a longer hospital stay. For these victims the medical costs further increase after the occurrence of the crash and remain on a higher level, even 4 years after the crash. These findings lead to the recommendation that when estimating longer term medical costs, one should also take into account different trajectories according to the characteristics of the victim population.

This detailed information allows policymakers and researchers to estimate medical costs more accurately by taking into account the variation for different subgroups of traffic victims and the total amount of costs on the long term. It also serves as an additional source of information when calculating the total burden of road injuries. Here the variation and total long-term costs should be taken into account. For example, the analyses show the high impact on medical costs of certain comorbidities. With an increasingly older population, the proportion of victims with comorbidities will increase, resulting in higher costs even if the total number of traffic victims stagnates or decreases. Furthermore, this detailed analysis can assist policymakers in improving policy aimed at reducing these medical costs.

\subsection{Factors influencing costs related to production loss}

Two studies were consulted to give an insight in the costs of serious road injuries related to production loss. Table 4 gives more details on these studies.

The average revenue loss resulting from a road crash is examined by Achit and Carnis [2]. This study indicated that the average revenue loss appears to increase with increasing injury severity, but the study also found that there is a threshold at a severity level of MAIS 3 . Furthermore, the study examined the influence of the professional category and found a large variation. The average revenue loss due to a road crash can differ between different professional categories due to a different average length of absence and different average wage levels.

Further, the study by Papadakaki et al. [20] identified the amount of indirect costs (which includes production loss) due to a road crash. Despite the absence of significant results, the study indicates a lower level of indirect costs among women, older victims and pedestrians. Contrary to the findings of Achit and Carnis [2] the study found the costs among victims with MAIS 1-2 to be slightly higher than those for victims with MAIS 3+ injuries. Especially this last finding needs further research.

These results provide insight into the determinants of production loss. They can help policymakers and researchers in estimating production loss for different types of injury severities by taking into account the victim's characteristics such as the professional category.

\section{A comparison of different approaches to estimate human costs}

Human costs represent the pain, grief, sorrow and mainly the loss of quality of life due to the injuries caused by a road crash [31]. Contrary to medical costs and costs related to production loss, the human costs of road casualties have no market value. To facilitate inclusion of these costs in a cost-benefit analysis, there are different approaches to attribute a monetary value to this type of consequences. Data analysis in section 2 has indicated that this cost component generally represents a very large share of the costs related to serious injuries 
Table 4 Description of the studies that provide more detailed analyses on medical costs

\begin{tabular}{lllll}
\hline & Database used & Dependent variable & Influencing factors & Country \\
\hline Achit \& Carnis (2014) [2] & $\begin{array}{l}\text { Five year cohort follow-up study with } \\
\text { 1372 patients that were admitted to } \\
\text { an emergency department of a hospital }\end{array}$ & Average revenue loss & $\begin{array}{l}\text { Injury severity, type of } \\
\text { professional category }\end{array}$ & $\begin{array}{l}\text { France, Rhône } \\
\text { department }\end{array}$ \\
Papadakaki et al., 2016 [20] & $\begin{array}{l}\text { One year cohort follow-up study with } \\
\text { 120 patients admitted in the intensive } \\
\text { care units of 7 hospitals }\end{array}$ & $\begin{array}{l}\text { Indirect costs (including } \\
\text { production loss) }\end{array}$ & $\begin{array}{l}\text { Age, gender, road user } \\
\text { type and injury severity }\end{array} \quad \begin{array}{l}\text { Germany, Greece } \\
\text { and Italy }\end{array}$ \\
\hline
\end{tabular}

and that variation in the method has a large influence on the cost estimates. This section will discuss and compare three approaches to estimate these costs: the Willingness To Pay (WTP) approach, the Quality Adjusted Life Years (QALYs) approach and the court awards approach.

\subsection{Different approaches to estimate human costs 4.1.1 Willingness to pay}

The WTP method is the method that is generally recommended to estimate human costs [31]. The survey on crash costs showed that the majority of the European countries use the WTP method, and that this method is related to the highest costs.

An (individual) WTP study estimates the amount of money a potential victim is willing to pay for a risk reduction. This amount is determined by the probability an adverse event (such as a road crash) occurs and the amount of distress the victim would suffer from this event. A WTP study gives a monetary value that potential victims are 'willing to pay' for a specific risk reduction. This value will be the result of a trade-off between money and loss of quality of life, and could be determined through a utility maximization process [15]. This value for a risk reduction gives an indication of the value of life (or the value of quality of life) as assigned by society. A WTP study does not measure the value of a specific individual life, but of a statistical (i.e. unspecified) life. The valuation occurs ex ante, before the incident occurs: it is the willingness to pay for reducing the probability of becoming a victim that is estimated [5]. Methods to asses this trade-off are based on actual behaviour (revealed preference) or by surveys in which respondents are asked how much they would pay for more safety (stated preference).

Most WTP studies focus on the value of a statistical life (VOSL) and thus on the estimation of human costs of fatalities. Information about the value of the quality of life and thus about the human cost of serious and slight injuries is relatively poor compared to the human costs of fatalities. WTP studies regarding injuries are very complex, among other reasons because of large variations in the severity of injuries and the impact of these injuries on the quality of life. Nevertheless, there are examples of thorough WTP studies in the UK [19], Sweden [21, 22] and Belgium [9]. In these studies, WTP methods are used to value the health impact of non-fatal road crashes in an indirect way. Using surveys, respondents are asked to make choices between different scenarios regarding health states resulting from a road crash. In these studies the value of an injury is determined relative to the VOSL. Next to that WTP studies can also determine the monetary valuation of road injuries in a direct way by asking how much money people are willing to pay for a lower non-fatal risk.

\subsubsection{QALY}

The QALY approach is mainly applied for cost-utility analyses in the field of public health, but can also be applied to road safety. A QALY expresses impacts of diseases or injuries on the quality of life combining the years of life lost (YLL) and years lived with disability (YLD). The severity of the injuries is expressed in disability weights, ranging from 0 (death) to 1 (perfect health). The QALY for a specific injury is calculated by multiplying the number of years lived with quality of life loss due to an injury, with a disability weight for this impact on quality of life. There exist different methods to determine the disability weights for specific injuries. For several injury categories, the number of QALYs is estimated and multiplied by a monetary value per QALY.

This monetary value per QALY reflects the human costs and is estimated using the WTP method. In general there are two approaches to estimate a WTP value of a QALY [23]. Firstly, the WTP can be derived directly by a contingent valuation study. In this approach people are asked about the amount of money they are willing to pay for a specific health improvement. Secondly, a monetary value of a QALY can be derived from the VOSL. Since the VOSL represents the value of all remaining life years at a specific age, it can be translated into a value per life year (which is equal to a QALY) on the basis of (average) age, life expectancy and a discount rate.

\subsubsection{Court awards}

In the court awards approach human costs are estimated as restitution costs to restore the road victim in its original state before the occurrence of the road crash. This approach uses the 'pretium doloris' compensations awarded by courts to traffic victims as an indication of human costs. The compensation for immaterial damage 
is not based on the individual preference of the road users, but consists of a judgement of a fair value by the judicial system. To be consistent with economic welfare theory, this value should reflect the trade-off individuals make between money and loss of quality of life, which is determined through a utility maximization process [15]. In general the estimations for human costs by courts are much lower than those obtained in WTP studies. The method is applied in a few countries, for example Germany [6] and Australia [8].

\subsection{A comparison between different approaches}

When selecting the appropriate method to estimate human costs of serious injuries for cost-benefit analyses the methods can be compared based on the quality of the resulting estimates and on their practicability. In this section the strengths and weaknesses of the methods are assessed by the reliability of their results, their level of detail, fairness, consistency with economic welfare theory, data availability and complexity. Consistency with economic welfare theory is crucial since this is the basis of cost-benefit analysis. This means that costs of serious injuries, as an input for cost-benefit analysis should be economic values that are recognized as expressions of individual/household preferences (see for example [7]). Moreover, values to be used in a cost-benefit analysis should be based on risks, which implies that the valuation of a risk reduction should occur ex ante [18, 24].

One of the strengths of the WTP method is that it is based on individual preferences, which implies that the method is consistent with economic welfare theory. Besides, the values are determined before the occurrence of the crash, so they can be used as an input for cost-benefit analyses. There exists a large consensus among researchers concerning the importance of individual choices. This technique is therefore used in different research areas to elicit the value of a risk reduction, for example environmental, transport, occupational and fire risks ([16]: [17]). On the other hand, the WTP method is criticized for its complex method for eliciting values for the quality of life. Especially stated preference methods where the trade-off between money and risk reduction is simulated by questionnaires in which people are asked how much they would pay for more safety, are prone to several potential biases. This leads to a large variability of results $[5,6]$. Furthermore, a WTP study only provides global information and cannot reflect the great diversity of types of road injuries, their severity and health consequences.

Since the QALY approach is based on a WTP value, this method shares most of the strengths and weaknesses of the WTP approach. However, while the QALY approach has not been commonly used to estimate costs of road injuries, it has a large advantage above the direct WTP approach: the great level of detail makes the QALY approach more applicable for valuing non-fatal injuries. The QALY concept has the ability to compare diseases and injuries with different impacts on mortality and morbidity, or in the case of road safety, fatalities and injuries of different severities. While direct WTP studies distinguish between only three to nine injury types or health states after a crash, the QALY approach enables estimating WTP values for a large diversity of injury types. However, it was found that values based on QALYs were lower than values based on direct WTP studies [25]. This is because the valuation of improving the quality of life appears to be lower than the estimation of extending life, and the direct WTP approach uses the value of life to derive human costs of injuries. Therefore, it can be argued that QALY values that are based on extending a life would result in an overestimation of human costs of non-fatal injuries. However, more research into the question of why the direct WTP approach results in higher values than the QALY approach is recommended.

A large advantage of the court awards approach is its practicability: the data is readily available and no complex study has to be conducted. However, the approach has some fundamental limitations. One of the major weaknesses is that the values in the court award approach are not based on individual preferences and therefore are not consistent with economic welfare theory. Furthermore, court award values are determined ex post and thus do not reflect the value of a risk reduction of the occurrence of an uncertain event. Next to that these values concern a specific individual case, and do not indicate the value of a statistical life. Moreover, the amounts awarded by judges vary widely. The level of compensation payments for immaterial costs is very dependent on the type of judicial system and the type of settlement. It is not always very clear how court amounts are defined and whether they actually compensate the victims.

Globally there exists very little information on the human costs of injuries. For future cost-benefit analyses, it can be recommended to use WTP studies or QALYs to estimate the monetary values of non-fatal road injuries, since these approaches accord to the principles of the economic welfare theory. QALYs are more complex to estimate but have the advantage of giving more detailed information on different types of injuries. Since there are different types of WTP methods as well as different methods to determine the value of a QALY, further research on the most suitable method to determine the monetary valuation of preventing road injuries is recommended. For costbenefit analyses it is not advised to use the court awards approach because of its unpredictability (the awards are among others highly dependent on the type of judicial system) and because it has no foundation in the economic welfare theory. 


\section{Conclusion}

Costs of road casualties are an important input variable to evaluate road safety measures. Since serious injuries are a relatively new road safety indicator, the research on this topic is still scarce. This paper presents the results of a review of these costs that was conducted in the framework of the H2020 project SafetyCube. Next to a comparison of the official cost estimates in European countries, three cost components that are most relevant for serious injuries are examined in more detail. The factors that influence medical costs and production loss are looked into and three approaches to put monetary values to human costs are discussed and compared.

The cost information that was collected by means of a survey in 32 European countries revealed that the costs related to serious injuries vary considerably between countries. The reported cost per serious injury varies between $€ 28,205$ and $€ 975,074$ and the total costs vary between $0.04 \%$ and $2.7 \%$ of a country's GDP. Differences can be explained by whether or not the WTP method is used for calculating the human costs, differences in the definition of a serious injury and differences in the cost components that are included. Moreover, the reporting rate of serious injuries appeared to be associated with the cost per serious injury. The relation of the level of road safety and the total costs was less clear. It is recommended to develop a common methodology for all European countries in order to enhance international comparability of cost estimates.

More detailed information on medical costs and production loss is given by national studies from different European countries. Age, socio-economic status, type of injury, injury severity, health status (pre-existing comorbidities) and road user type appear to have a significant influence on the medical costs attributable to a road crash. Particularly older victims with a worse health status (and more comorbidities) show higher acute and long term costs. This has implications for researchers and policymakers in assessing the (future) medical costs of potential traffic victims. Furthermore the importance of assessing medical costs on the long term was shown. The studies found a significantly higher level of medical costs attributable to the road crash the first year after the crash.

Concerning production loss, it was shown that revenue loss increases when injury severity is higher, although MAIS 4 and MAIS 5 injuries do not lead to much higher production losses than MAIS 3 injuries. Furthermore, the revenue loss differs between professional groups, which could be explained by the average wage and the average length of absence inherent to a certain profession.

With regards to human costs of serious injuries, most countries use the WTP method. This method is compared with two alternative approaches: the QALY approach and the court awards approach. Whereas WTP studies are mainly constituted to measure the human costs of fatalities, WTP studies that specifically estimate the human costs of non-fatal injuries are rare and rather limited in the specification of road injuries. Using the WTP method to estimate the value of QALYs on the other hand gives the possibility of providing values for a large diversity of injury types.

While the WTP approach and the QALY approach use complex studies, for which there are some methodological issues, the court awards approach makes use of existing information. The compensation payments to road injuries awarded by courts are in most cases however much lower than the values obtained in the other methods and are characterized by a huge unpredictability since they are highly dependent on the judicial system. Since these values are not based on individual preferences and they are determined ex post and apply to a specific case, it is advised not to use them in a costbenefit analysis. WTP and QALY approaches are more suitable for determining the monetary valuation of preventing road injuries to be used in cost-benefit analysis. Given the diversity of these methods, further research on WTP and QALY methods is recommended.

\section{Abbreviations}

GDP: Gross Domestic Product; MAIS: Maximum Abbreviated Injury Scale; PPP: Purchasing Power Parities; QALY: Quality Adjusted Life Year; VOSL: Value Of a Statistical Life; WTP: Willingness To Pay; YLL: Years of Life Lost;

YLD: Years Lived with Disability

\section{Acknowledgements}

The authors thank Ward Vanden Berghe (Vias institute) for his support in the data cleaning and analysis.

\section{Authors' contributions}

The author(s) read and approved the final manuscript.

\section{Funding}

This paper is based on work carried out within the SafetyCube research project of the H2020 programme of the European Commission (Grant number 633485). The information and views set out in this paper are those of the authors and may not reflect the official opinion of the European Commission.

Availability of data and materials

The dataset used in the study is available from the corresponding author on reasonable request.

\section{Competing interests}

The authors declare they have no competing interests.

\section{Author details}

${ }^{1}$ Vias institute, Brussels, Belgium. ${ }^{2}$ W2Economics, Utrecht, Netherlands, ${ }^{3}$ Université Gustave Eiffel, Champs-sur-Marne, France. ${ }^{4}$ SWOV Institute for Road Safety Research, The Hague, Netherlands. ${ }^{5}$ Transportøkonomisk institutt, Oslo, Norway. ${ }^{6}$ Medizinische Hochschule Hannover, Hanover, Germany.

Received: 6 January 2020 Accepted: 2 October 2020

Published online: 29 October 2020

References

1. Achit, H. (2015). Analyse économique des préjudices et des indemnisations des accidents de la circulation routière : une approche par la victime (Doctoral dissertation). France: Université Paris-Est. 
2. Achit, H., \& Carnis, L. (2014). Physical impairment and medical care spending for road crash victims. Securitas Vialis, 18, 36-53.

3. Alfaro, J. L., Chapuis, M., \& Fabre, F. (Eds.) (1994). Socio-economic COST of road accidents: Final report of action COST 313. Brussels: Commission of the European Community.

4. Association for the Advancement of Automotive Medicine. (n.d.) Abbreviated Injury Scale. Retrieved on July 27, 2020 on https://www.aaam. org/abbreviated-injury-scale-ais/

5. Bahamonde-Birke, F. J., Kunert, U., \& Link, H. (2015). The value of a statistical life in a road safety context - A review of the current literature. Transport Reviews, 35(4), 488-511.

6. Baum, H., Kranz, T., \& Westerkamp, U. (2010). Volkswirtschaftliche Kosten durch Straßenverkehrsunfälle in Deutschland. (Heft M 208). Bergisch Gladbach: Bundesanstalt für Straßenwesen.

7. Boardman, A. E., Greenberg, D. H., Vining, A. R., \& Weimer, D. L. (2011). Costbenefit analysis. Concepts and practice, (4th ed., ). Upper Saddle River: Prentice Hall.

8. Bureau of Infrastructure, Transport and Regional Economics (2009). Road crash costs in Australia 2006 (Report No. 118). Canberra: Department of Infrastructure, Transport, Regional Development and Local Government.

9. De Brabander, B. (2006). Valuing the reduced risk of road accidents. Empirical estimates for Flanders based on stated preference methods (Doctoral dissertation). Diepenbeek: Hasselt University.

10. Devos, S. (2017). Direct medical costs of transport: The case of air pollution and traffic injuries (Doctoral dissertation). Brussels: Vrije Universiteit Brussel.

11. Devos, S., van Belleghem, G., Van Lier, T., Annemans, L., \& Putman, K. (2017). Attributable health care costs of traffic victims until 1 year after hospitalisation. Journal of Transport \& Health, 4, 171-179.

12. Elvik, R. (2000). How much do road accidents cost the national economy? Accident Analysis \& Prevention, 32(6), 849-851.

13. European Commission (2010). Communication from the commission to the European Parliament, the council, the European economic and social committee and the Committee of the Regions: Towards a European road safety area: Policy orientations on road safety 2011-2020. Brussels: European Commission.

14. European Commission (2013). Commission staff working document on the implementation of objective 6 of the European Commission's policy orientations on road safety 2011-2020: First milestone towards and injury strategy, SWD(2013) 94 final (). Brussels: European Commission.

15. Jones-Lee, M. (1976): The Value of Life. London: Martin Robertson. (Ed.) (1982): The value of life and safety. Amsterdam: North-Holland

16. Lindhjem, H., Navrud, S., Braathen, N. A., \& Biausque, V. (2011). Valuing mortality risk reductions from environmental, transport and health policies; a global meta-analysis of stated preference studies. Risk Analysis., 31(9), 1381-1407.

17. Miller, T. R. (2000). Variations between countries in values of statistical life variations between countries in values of statistical life. Journal of Transport Economics and Policy, 34(2), 169-188.

18. Mishan, E. J. (1971). Evaluation of life and limb: A theoretical approach Journal of Political Economy, 79, 687-705.

19. O'Reilly, D., Hopkin, J., Loomes, G., Jones-Lee, M., Philips, P., McMahon, K., ... Kemp, R. (1994). The value of road safety - UK research on the valuation of preventing non-fatal injuries. Journal of Transport Economics and Policy, 28(1), 45-59.

20. Papadakaki, M., Stamouli, M.-A., Ferraro, O. E., Orsi, C., Otte, D., \& Tzamalouka, G. ... Chliaoutakis, J. (2016). Hospitalization costs and estimates of direct and indirect economic losses due to injury sustained in road traffic crashes: Results from a one-year cohort study in three European countries (the REHABILAID project). Trauma, 19(4), 243-253.

21. Persson, U. (2004). Valuing reductions in the risk of traffic accidents based on empirical studies in Sweden (Doctoral dissertation). Lund: Lund Institute of Technology.

22. Persson, U., Norinder, A., \& Svensen, M. (1995). Valuing the benefits of reducing the risk of non-fatal road injuries: The Swedish experience. In C. Schwab, \& N. Soguel (Eds.), Contingent valuation, transport safety and the value of life, (pp. 63-84). Boston: Kluwer Academic Publishers.

23. Ryen, L., \& Svensson, M. (2014). The willingness to pay for a quality adjusted life year: A review of the empirical literature. Health Economics, 24(10), 12891301.
24. Schelling, T. C. (1968). The life you save may be your own. In S. B. Chase (Ed. 1, Problems in public expenditure analysis, (pp. 127-176). Washington, DC: The Brookings Institution.

25. Schoeters, A., Wijnen, W., Carnis, L., Weijermars, W., Elvik, R., \& Johanssen, H. ... Daniels, S. (2017). Costs related to serious injuries, deliverable 7.3 of the H2020 project SafetyCube.

26. Trawén, A., Maraste, P., \& Persson, U. (2002). International comparison of costs of a fatal casualty of road accidents in 1990 and 1999. Accident Analysis \& Prevention, 34(3), 323-332.

27. Weijermars, W., Bos, N., \& Stipdonk, H. L. (2015). Serious road injuries in the Netherlands dissected. Traffic Injury Prevention, 17(1), 73-79.

28. Weijermars, W., Bos, N., Schoeters, A., Meunier, J.-C., Nuyttens, N., ... Thomas, P. (2018). Serious road traffic injuries in Europe, lessons from the EU research project SafetyCube. Transportation Research Record, 2672(32), 1-9.

29. Wijnen, W., \& Stipdonk, H. (2016). Social costs of road crashes: An international analysis. Accident Analysis and Prevention, 94, 97-106.

30. Wijnen, W., Weijermars, W., Schoeters, A., Vanden Berghe, W., Bauer, R., Carnis, L., Martensen, H. (2019). An analysis of official road crash cost estimates in European countries. Safety Science, 113, 318-327.

31. Wijnen, W., Weijermars, W., Vanden Berghe, W., Schoeters, A., Bauer, R. Carnis, L., ... Martensen, H. (2017). Crash cost estimates for European countries, deliverable 3.2 of the H2020 project SafetyCube.

\section{Publisher's Note}

Springer Nature remains neutral with regard to jurisdictional claims in published maps and institutional affiliations.

\section{Submit your manuscript to a SpringerOpen ${ }^{\circ}$ journal and benefit from:}

- Convenient online submission

- Rigorous peer review

- Open access: articles freely available online

High visibility within the field

- Retaining the copyright to your article

Submit your next manuscript at $\boldsymbol{\nabla}$ springeropen.com 